\title{
The affinity of $\mathrm{Si}-\mathrm{N}$ and $\mathrm{Si}-\mathrm{C}$ bonding in amorphous silicon carbon nitride $(\mathrm{a}-\mathrm{SiCN})$ thin film
}

\author{
C.W. Chen ${ }^{\mathrm{a}, *}$, C.C. Huang ${ }^{\mathrm{a}}$, Y.Y. Lin ${ }^{\mathrm{a}}$, L.C. Chen ${ }^{\mathrm{b}}$, K.H. Chen ${ }^{\mathrm{c}}$ \\ ${ }^{a}$ Department of Materials Science and Engineering, National Taiwan University, 1, Roosevelt Road, Sec. 4, Taipei 106, Taiwan \\ ${ }^{\mathrm{b}}$ Center for Condensed Matter Sciences, National Taiwan University, Taipei, Taiwan \\ ${ }^{\mathrm{c}}$ Institute of Atomic and Molecular Sciences, Academic Sinica, Taipei, Taiwan
}

Available online 2 February 2005

\begin{abstract}
The bonding sensitivities of $\mathrm{Si}-\mathrm{N}$ and $\mathrm{Si}-\mathrm{C}$ bonds in the a-SiCN thin films were investigated experimentally and theoretically. It was found that a sharp phase transition from the predominantly $\mathrm{Si}-\mathrm{C}$ bonded structure to the $\mathrm{Si}-\mathrm{N}$ bonded structure occurs during the deposition of SiCN thin films without and with $\mathrm{N}$ incorporation. The stronger affinity of silicon to bond with nitrogen than to bond with carbon results in the complete absence of $\mathrm{Si}-\mathrm{C}$ bonds in a-SiCN thin films. These were further verified by the analyses of crystal structures and local bonding configurations, morphology, and optical properties. Finally, the relative stabilities of $\mathrm{Si}-\mathrm{C}$ and $\mathrm{Si}-\mathrm{N}$ bonds in the a-SiCN network were studied by the ab initio calculations for the simple $\mathrm{SiCN}$ clusters. The local atomic structure with $\mathrm{Si}-\mathrm{N}-\mathrm{C}($ or $\mathrm{Si}-\mathrm{N}=\mathrm{C}$ ) bonding exhibits a considerably lower total energy of $0.65(0.52) \mathrm{eV}$ than that with $\mathrm{Si}-\mathrm{C}-\mathrm{N}(\mathrm{Si}-\mathrm{C}=\mathrm{N})$ bonding, providing the explanation of the stronger affinity of $\mathrm{Si}-\mathrm{N}$ bonds than $\mathrm{Si}-\mathrm{C}$ bonds in a-SiCN thin films.
\end{abstract}

(C) 2004 Elsevier B.V. All rights reserved.

Keywords: Amorphous silicon carbon nitride; Bonding affinity; XPS; Ab initio

\section{Introduction}

The syntheses of ternary $\mathrm{Si}-\mathrm{C}-\mathrm{N}$ materials have been attracting growing interest due to their excellent physical properties, such as high hardness [1], oxidation resistance [2] and high thermal diffusivity [3]. In addition, crystalline SiCN films exhibited a wide band gap of $3.8 \mathrm{eV}$, suitable for optoelectronic application in the blue-UV range [4]. Several techniques have been developed to produce various kinds of $\mathrm{Si}-\mathrm{C}-\mathrm{N}$ composite $(\mathrm{SiCN})$ films. For example, amorphous SiCN films synthesized by thermal chemical vapor deposition (CVD) techniques showed a hardness in the range of 27-38 GPa and a stiffness of 224-289 GPa [1], whereas a-SiCN films deposited by electron cyclotron resonance plasma CVD

\footnotetext{
* Corresponding author. Tel.: +886 2 33665202; fax: +886223634562.

E-mail address: chunwei@ntu.edu.tw (C.W. Chen).
}

possessed a hardness of $22 \mathrm{GPa}$ [5]. The physical properties depend, not only on the composition, but also on the chemical bonding and local atomic order of constituent elements in the films, which are strong functions of the process parameters. Compared to the hardness predicted for the hypothetical $\beta-\mathrm{C}_{3} \mathrm{~N}_{4}$ [6], the values measured for the $\mathrm{Si}-\mathrm{C}-\mathrm{N}$ materials were much lower, although the addition of silicon was expected to promote the formation of $\mathrm{sp}^{3}$-hybridization of carbons bonds and also of the additional bonds with nitrogen [7]. Structural and local bonding analyses of $\mathrm{SiCN}$ films performed by X-ray diffraction (XRD) spectroscopy and $\mathrm{X}$-ray-absorption near-edge structure (XANES) suggested that $\mathrm{SiCN}$ demonstrates similar local atomic structure to $\alpha-\mathrm{Si}_{3} \mathrm{~N}_{4}$ with the substitution of $\mathrm{C}$ atoms only for the $\mathrm{Si}$ sites [8]. High resolution X-ray photoelectron spectroscopy (XPS) scans of $\mathrm{Si}(2 \mathrm{p}), \mathrm{C}(1 \mathrm{~s})$ and $\mathrm{N}(1 \mathrm{~s})$ peaks reveal $\mathrm{Si}-\mathrm{N}$ peak as well as $\mathrm{C}-\mathrm{N}$ and $\mathrm{C}=\mathrm{N}$ peaks but undetectable $\mathrm{Si}-\mathrm{C}$ signal for $\mathrm{SiCN}$ films prepared by different CVD techniques [9]. The origin of the complete 
absence of $\mathrm{Si}-\mathrm{C}$ bond in the $\mathrm{SiCN}$ network is still not clear. To explore the knowledge of bonding sensitivity in the a-SiCN films becomes crucial to understand the basic physics for future applications.

In this study, various compositions of $\mathrm{Si}, \mathrm{C}$ and $\mathrm{N}$ in the a-SiCN films were studied systematically to investigate the bonding sensitive properties in a-SiCN films. The physical properties of structural, chemical bonding, surface morphology, and optical properties were characterized by XRD, XPS, scanning electron microscopy (SEM) and the microreflectometry system respectively, were performed to characterize the structural and chemical bonding properties. In parallel, the $a b$ initio total energy calculations were performed to study the stabilities of local bonding configurations in a-SiCN film using the cluster model approximation. The information is expected to improve the understanding of the mechanism governing the bonding sensitivity in a-SiCN films.

\section{Experimental methods}

Microwave CVD systems (MW-CVD, AsTex, $5 \mathrm{~kW}$ ) were employed to grow the $\mathrm{SiCN}$ films on the $\mathrm{Si}(100)$ and fused silica substrates respectively. Details of the MW-CVD systems have been described elsewhere [9]. In brief, a 1.5 $\mathrm{kW}$ microwave source was employed to generate plasma as a mixture of semiconductor grade $\mathrm{SiH}_{4}, \mathrm{NH}_{3}, \mathrm{CH}_{4}$ and $\mathrm{H}_{2}$ gases in various proportions was used to deposit a-SiCN thin films. By adjusting the flow rate ratio of different gases, films with various compositions were obtained. A microwave power of $1000 \mathrm{~W}$ was set and the chamber pressure was kept about $3.73 \mathrm{kPa}$ during deposition. In order to systematically investigate the bonding sensitivities of a$\mathrm{SiCN}$ films, we performed the experiments by varying the $\mathrm{NH}_{3}$ or $\mathrm{CH}_{4}$ flow rates and by keeping other gas flow rates constant during deposition. Incorporation of hydrogen in the film is inevitable in most CVD process. It has been reported that the a-SiCN films with and without hydrogen incorporation prepared by CVD and ion-beam sputtering deposition (IBS), respectively, show similar chemical compositions and bonding states of $\mathrm{C}, \mathrm{N}$, and $\mathrm{Si}$. Incorporation of hydrogen assists the formation of $\mathrm{C}-\mathrm{H}, \mathrm{N}-\mathrm{H}$ and $\mathrm{Si}-\mathrm{H}$ bonds in the films, resulting in the termination of dangling bonds of the a-SiCN network [5]. The chemical composition and bonding states of the a-SiCN films were determined by a PerkinElmer Phi 1600 XPS system with a $(800-\mu \mathrm{m})^{2}$ sampling area and $11.75 \mathrm{eV}$ pass energy. $\mathrm{MgK}_{\alpha}$ radiation of 1253.6 $\mathrm{eV}$ was used as the X-ray source, with a line width of 0.7 $\mathrm{eV}$. To obtain information about the chemical bonding states, scans of $\mathrm{Si}(2 \mathrm{p}), \mathrm{C}(1 \mathrm{~s})$, and $\mathrm{N}(1 \mathrm{~s})$ peaks of a-SiCN films were performed. Optical properties of refractive index, transmittance and film thickness were determined by the spectral micro-reflectometry (Mission peaks optics), which allows optical measurements in the UV-visible range of wavelength $(250-1000 \mathrm{~nm})$.

\section{Structural simulation}

This paper concerns the nature of the bonding sensitivity of $\mathrm{Si}, \mathrm{C}, \mathrm{N}$ in a-SiCN films. We have calculated the total energy of various $\mathrm{Si}, \mathrm{C}, \mathrm{N}$ configurations based on the simple cluster model with the bonds at the cluster surface terminated by hydrogen rather than use the periodic amorphous network as others [10]. This will mimic the local environment at the stage when the formation of chemical bonds from the dissociated gas during deposition is taking place. The total energy and electronic structure calculations were performed using the CASTEP code and the detailed simulation method has been described elsewhere [11].

\section{Results and discussions}

In order to investigate the bonding sensitivities of $\mathrm{Si}, \mathrm{C}$ and $\mathrm{N}$ in a-SiCN films, we systematically varied the compositions of the films by controlling the flow rate ratio for different gases. Firstly, we varied the $\mathrm{NH}_{3}$ flow rate gradually from 0 to $30 \mathrm{sccm}$ and kept the flow rates of $\mathrm{SiH}_{4}$ $3 \mathrm{sccm}, \mathrm{CH}_{4} 30 \mathrm{sccm}$ and $\mathrm{H}_{2} 100 \mathrm{sccm}$ unchanged during deposition. With the XPS scans of C(1s), N(1s), and $\mathrm{Si}(2 \mathrm{p})$ peaks, information about the bonding behavior could be obtained. Fig. 1(a),(b) shows the XPS spectra of the deposited films without and with the addition of $\mathrm{NH}_{3}$ gas. For $\mathrm{Si}(2 \mathrm{p})$ spectra, the 99.2-, 100.3-, 102,7- and 104.6-eV peaks are attributed to the $\mathrm{Si}(2 \mathrm{p})-\mathrm{Si}$, the $\mathrm{Si}(2 \mathrm{p})-\mathrm{C}$, and $\mathrm{Si}(2 \mathrm{p})-\mathrm{N}$ and $\mathrm{Si}(2 \mathrm{p})-\mathrm{O}$ bonds, respectively. For the film without $\mathrm{NH}_{3}$ addition, the XPS spectrum belonging to the $\mathrm{Si}(2 \mathrm{p})$ with strong peak at $100.3 \mathrm{eV}$ is the signature of the $\mathrm{Si}-\mathrm{C}$ bonds and the spectra belonging to the $\mathrm{C}(1 \mathrm{~s})$ content with peaks centered at 282.8 and $284.6 \mathrm{eV}$ are the signatures of $\mathrm{C}-\mathrm{Si}$ and $\mathrm{C}-\mathrm{C}$, respectively, indicating the mixing phases of $\mathrm{SiC}$ and diamond-like carbon. As we slowly increased the $\mathrm{NH}_{3}$ content, a significant phase transition was observed. Fig. 1(b) shows the XPS spectra of the a-SiCN sample with a composition of $20 \% \mathrm{C}, 35 \% \mathrm{~N}, 41 \% \mathrm{Si}$ and $4 \% \mathrm{O}$ after the addition of $\mathrm{NH}_{3}$ with a flow rate of $6 \mathrm{sccm}$ (the minimum detectable flow rate for our nitrogen mass flow controller). The contribution at $102.0 \mathrm{eV}$ in the $\mathrm{Si}(2 \mathrm{p})$ peak is related to $\mathrm{Si}-\mathrm{N}$, suggesting that the major part of $\mathrm{Si}$ within the film was bonded to $\mathrm{N}$ with a complete vanish of the $\mathrm{Si}-\mathrm{C}$ signal at the energy of $100.3 \mathrm{eV}$. For the $\mathrm{C}(1 \mathrm{~s})$ and $\mathrm{N}(1 \mathrm{~s})$ peaks, 285.9 and $287.7 \mathrm{eV}$ as well as $397.8,398.3$ and $400.1 \mathrm{eV}$, are attributed to $\mathrm{sp}^{2}$ trigonal $\mathrm{C}=\mathrm{N}$ bonding, $\mathrm{C}-\mathrm{N}$ bonds, $\mathrm{N}-$ Si bonds, $\mathrm{N}-\mathrm{C}$ bonds, and $\mathrm{N}$ bonded to an $\mathrm{sp}^{2}$-hybridized $\mathrm{C}$, respectively. There are no major peaks that match the $\mathrm{C}-\mathrm{Si}$ bonding energy at $282.8 \mathrm{eV}$ or the $\mathrm{Si}-\mathrm{C}$ binding energy at $100.3 \mathrm{eV}$, suggesting the absence of $\mathrm{Si}-\mathrm{C}$ bonds in the aSiCN film after $\mathrm{NH}_{3}$ gas was introduced during deposition. This result can be further verified by XRD spectra as shown in Fig. 2(a) and (b). The two pronounced diffraction peaks located at $2 \theta \cong 33$ and $35.8^{\circ}$ in Fig. 2(a) correspond to the 

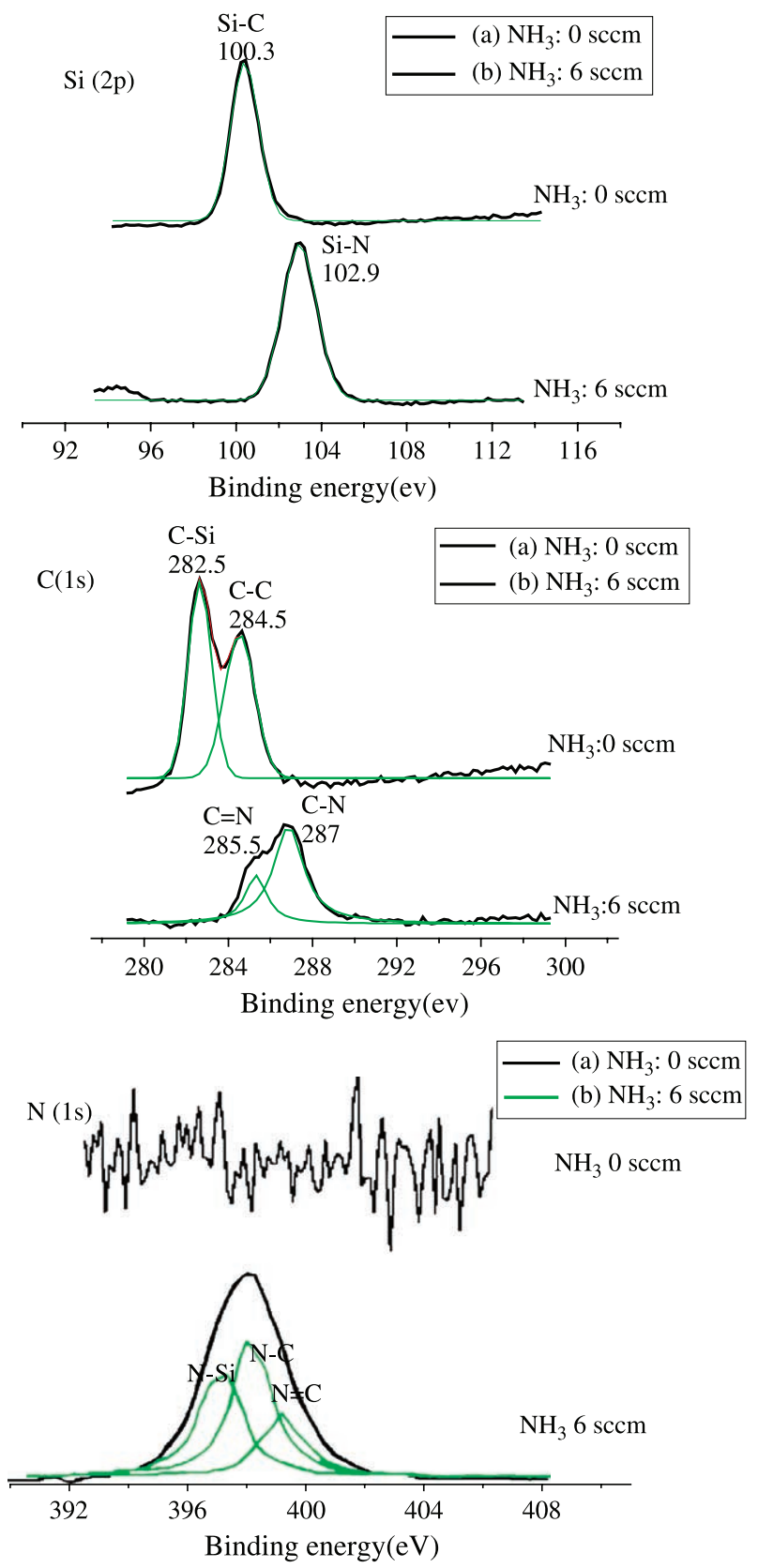

Fig. 1. High resolution XPS of the thin films deposited by us varying the $\mathrm{NH}_{3}$ flow rate (a) $0 \mathrm{sccm}$ and (b) $6 \mathrm{sccm}$ and by keeping the constant flow rates of $\mathrm{SiH}_{4} 3 \mathrm{sccm}, \mathrm{CH}_{4} 30 \mathrm{sccm}$ and $\mathrm{H}_{2} 100 \mathrm{sccm}$.

$\mathrm{Si}(100)$ substrate background and the 3C-SiC crystal, respectively, indicating the formation of the $\mathrm{SiC}$ crystal under the condition without any addition of $\mathrm{NH}_{3}$. Fig. 2(b) shows the XRD spectrum of the a-SiCN film after the incorporation of $\mathrm{NH}_{3}$ gas. In addition to the signal of the $\mathrm{Si}(100)$ substrate background, no peak was observed, indicating the formation of amorphous phase. The SEM micrographs of the thin films in Fig. 3 show the transition from the $\mathrm{SiC}$ nanocrystalline phase to the amorphous $\mathrm{SiCN}$ phase after $\mathrm{N}$ incorporation. The stronger affinity of silicon to bond with nitrogen than to bond with carbon suggests the local bonding structure of $\mathrm{SiCN}$ is similar to $\mathrm{Si}_{3} \mathrm{~N}_{4}$ with $\mathrm{C}$ atoms substitution only for the Si sites. This result is further evident by the spectra of the refractive index for the films without and with $\mathrm{N}$ incorporation as shown in Fig. 4. The dispersion of the refractive index for the film without $\mathrm{N}$ incorporation exhibits a value from 2.5 to 2.65 close to that of $\mathrm{SiC}(\sim 2.6)$. On the other hand, the refractive index of the film with $\mathrm{N}$ incorporation varies from 2.1 2.15 close to that of $\mathrm{Si}_{3} \mathrm{~N}_{4}(\sim 2.0)$.

Next, we carried out a series of experiments by varying the $\mathrm{CH}_{4}$ flow rate from 0 to $30 \mathrm{sccm}$ and keeping the flow rates of $\mathrm{SiH}_{4} 3 \mathrm{sccm}, \mathrm{NH}_{3} 20 \mathrm{sccm}$ and $\mathrm{H}_{2} 100 \mathrm{sccm}$ unchanged during deposition. The dependence of compositions of the $\mathrm{SiCN}$ films as a function of the $\mathrm{CH}_{4}$ flow rate is shown in Fig. 5(a). It is shown that the $\mathrm{C}$ content in the $\mathrm{SiCN}$ films gradually increases with the increasing $\mathrm{CH}_{4}$ flow rate up to $15 \mathrm{sccm}$ and reaches to a value around $25 \%$ for the $30 \mathrm{sccm} \mathrm{CH}_{4}$ flow rate. No significant variation of carbon content has been found in the a-SiCN thin films with further increasing the $\mathrm{CH}_{4}$ flow rate under current experimental conditions. The XPS spectra (not shown here) for all these samples demonstrate similar signatures to those obtained in Fig. 1(b) but only with the variations of the area ratio of $\mathrm{C}-\mathrm{N} / \mathrm{C}=\mathrm{N}$ (or $\mathrm{N}-\mathrm{C} / \mathrm{N}=\mathrm{C}$ ) in the $\mathrm{C}(1 \mathrm{~s}$ ) (or $\mathrm{N}(1 \mathrm{~s})$ )spectra. All the Si atoms are found to bond to $\mathrm{N}$ with no detectable $\mathrm{Si}-\mathrm{C}$ signal. The absence of the peaks that
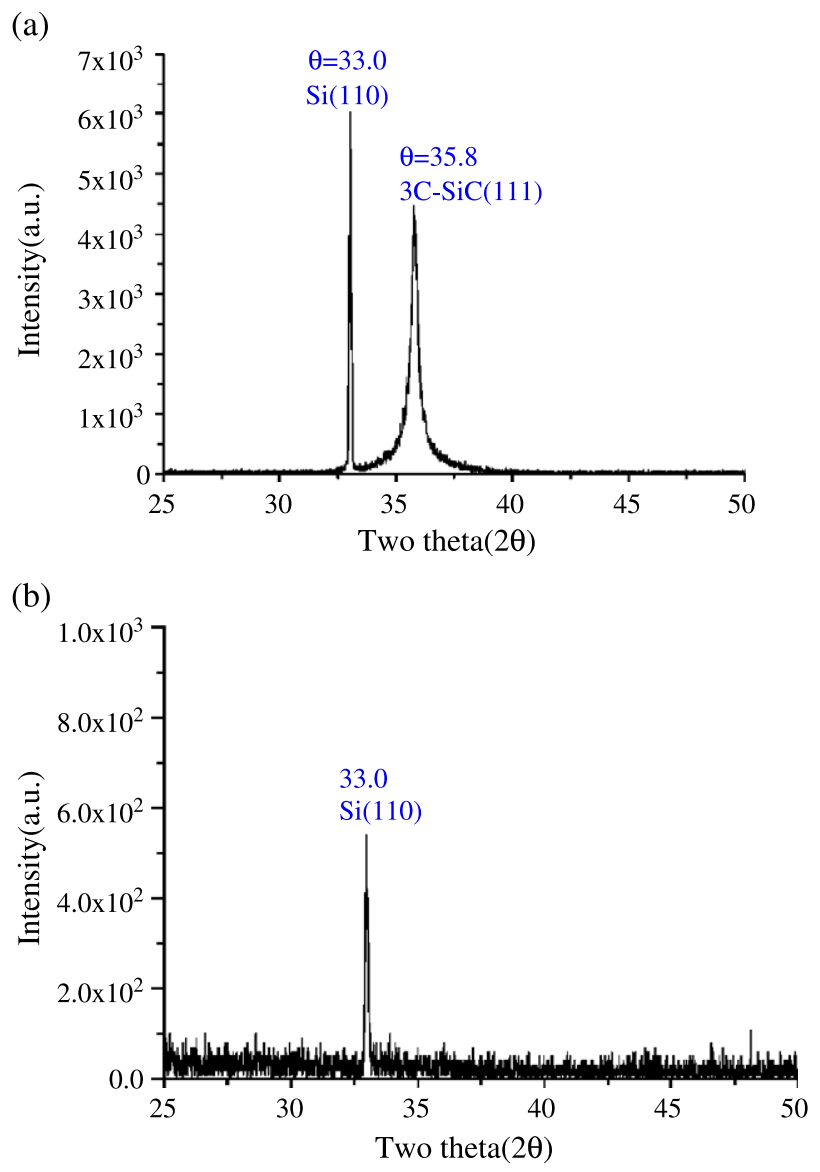

Fig. 2. X-ray diffraction spectra of (a) $\mathrm{SiC}$ nanocrystalline and (b) a-SiCN thin film. 
(a)

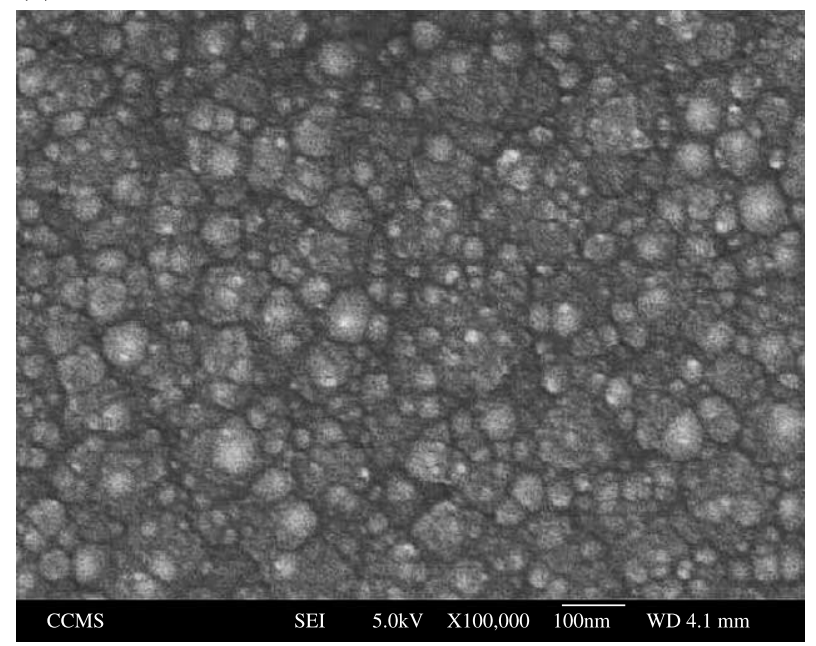

(b)

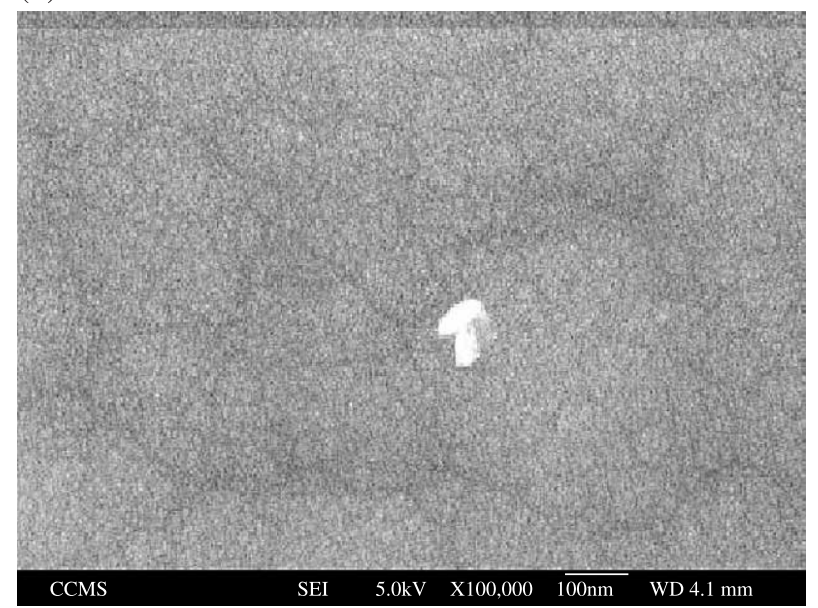

Fig. 3. SEM surface morphology of (a) $\mathrm{SiC}$ nanocrystalline and (b) a-SiCN thin film.

match the $\mathrm{C}-\mathrm{Si}$ and $\mathrm{Si}-\mathrm{C}$ binding energies again support the strong affinity of $\mathrm{Si}-\mathrm{N}$ bonding compared to the $\mathrm{Si}-\mathrm{C}$ bonding in the $\mathrm{SiCN}$ thin films during deposition. As the $\mathrm{C}$ content increases in the $\mathrm{SiCN}$ film, the intensities of $\mathrm{C}=\mathrm{N}$

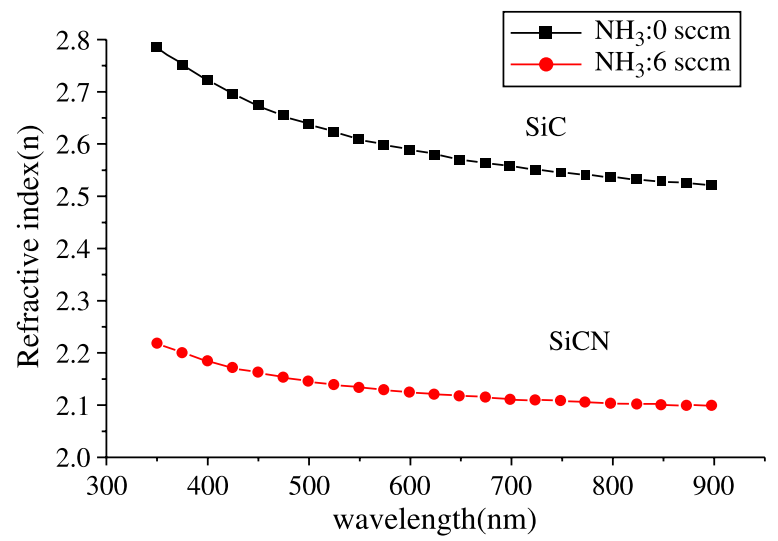

Fig. 4. The dispersion of optical refractive index of the thin films deposited without and with $\mathrm{N}$ incorporation. (a)

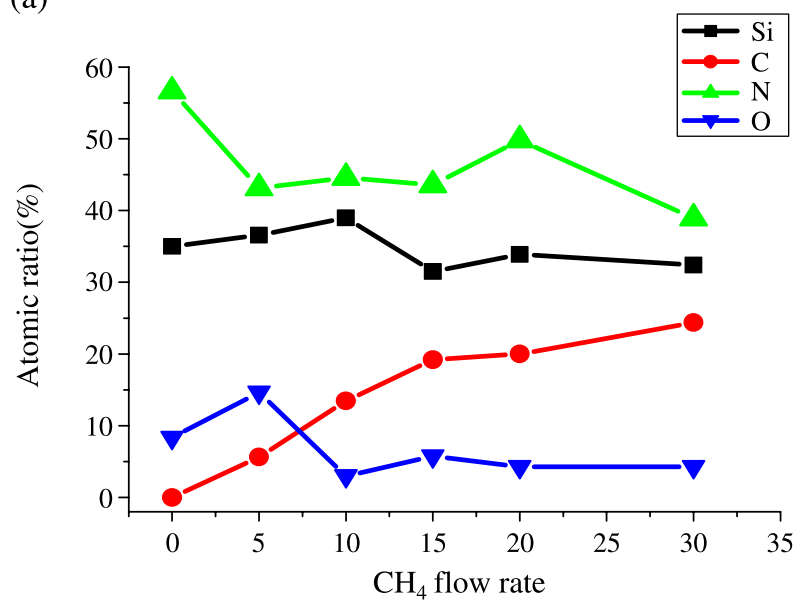

(b)

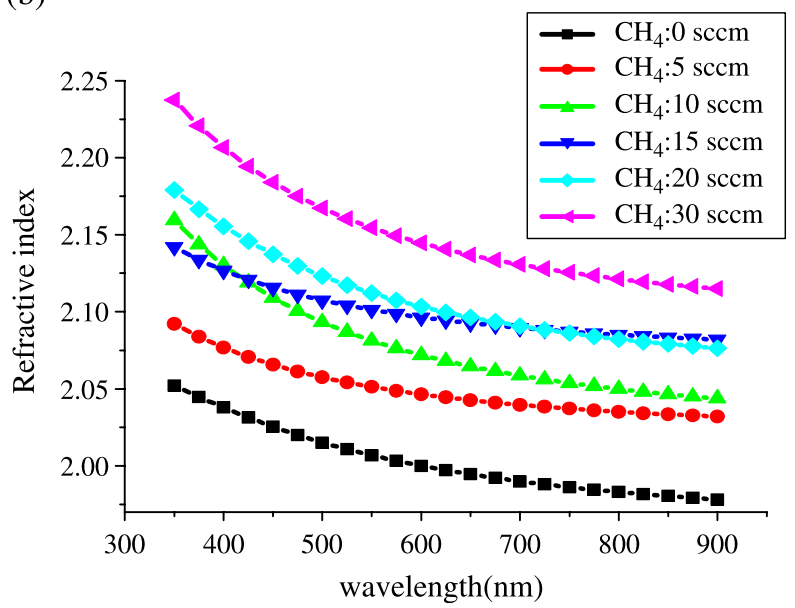

Fig. 5. (a) The dependence of compositions of the $\mathrm{SiCN}$ films as a function of the $\mathrm{CH}_{4}$ flow rate. (b) The dispersion of refractive index for a-SiCN thin films with various carbon content.

bond signals in both $\mathrm{C}(1 \mathrm{~s})$ and N(1s) XPS spectra also enhance, indicating the difficulty to keep $\mathrm{sp}^{3}$-bonded $\mathrm{C}$ atoms in the a-SiCN network when the carbon content increases. This result is consistent with the physical properties of the thermal diffusivity, density and hardness of a-SiCN thin films decreased with increasing carbon content [3]. The dispersion of refractive index for a-SiCN thin films with various carbon content is shown in Fig. 5(b). The refractive index values $n(\lambda)$ of the a-SiCN thin films increase as the carbon content increases. The refractive index of the a-SiCN thin films varies from $\sim 2.0$ to $\sim 2.2$

Table 1

The relative stability of $\mathrm{Si}-\mathrm{C}-\mathrm{N}$ and $\mathrm{Si}-\mathrm{N}-\mathrm{C}$ clusters (or $\mathrm{Si}-\mathrm{C}=\mathrm{N}$ and $\mathrm{Si}-$ $\mathrm{N}=\mathrm{C}$ ) clusters by taking the total energy of $\mathrm{Si}-\mathrm{C}-\mathrm{N}$ (or $\mathrm{Si}-\mathrm{C}=\mathrm{N}$ ) as zero

\begin{tabular}{lll}
\hline & $\mathrm{Si}-\mathrm{C}-\mathrm{N}$ & $\mathrm{Si}-\mathrm{N}-\mathrm{C}$ \\
\hline Energy $(\mathrm{eV})$ & 0 & -0.67 \\
& $\mathrm{Si}-\mathrm{C}=\mathrm{N}$ & $\mathrm{Si}-\mathrm{N}=\mathrm{C}$ \\
\hline Energy $(\mathrm{eV})$ & 0 & -0.52 \\
\hline
\end{tabular}

The unsaturated bonds are saturated by $\mathrm{H}$ atoms. 
while the carbon content changes from $0 \%$ to $25 \%$. These values are relatively closer to that of $\mathrm{Si}_{3} \mathrm{~N}_{4}(\sim 2.0)$ compared to that of $\mathrm{SiC}(\sim 2.6)$ due to the similarities of local bonding configurations between $\mathrm{SiCN}$ and $\mathrm{Si}_{3} \mathrm{~N}_{4}$ as mentioned above.

The total energies of the possible configurations for the $\mathrm{SiCN}$ clusters calculated by the ab initio method are shown in Table 1. The unsaturated bonds in all configurations were terminated by hydrogen atoms to avoid the boundary effects. It is clearly shown that the $\mathrm{Si}-\mathrm{N}-\mathrm{C}$ cluster has a much higher stability compared to the $\mathrm{Si}-\mathrm{C}-\mathrm{N}$ cluster with a lower energy about $0.65 \mathrm{eV}$. This value is considerably large in the small molecular cluster approximation. The $\mathrm{Si}-\mathrm{N}$ exhibits a shorter bond length of $1.69 \AA$ than that of $\mathrm{Si}-\mathrm{C}$ of $1.86 \AA$. The energetics of local bonding configurations suggests that strong affinity to form $\mathrm{Si}-\mathrm{N}$ rather than to form $\mathrm{Si}-\mathrm{C}$ occurs for the dissociated gas radicals of $\mathrm{Si}, \mathrm{N}, \mathrm{C}, \mathrm{H}$ during chemical vapor deposition. The $\mathrm{Si}-\mathrm{N}=\mathrm{C}$ cluster with the $\mathrm{Si}-\mathrm{N}$ bond length of $1.71 \AA$ also shows a lower energy of $0.52 \mathrm{eV}$ than the $\mathrm{Si}-\mathrm{C}=\mathrm{N}$ cluster with the $\mathrm{Si}-\mathrm{C}$ bond length of $1.87 \AA$.

\section{Conclusion}

The bonding sensitivities of $\mathrm{Si}-\mathrm{N}$ and $\mathrm{Si}-\mathrm{C}$ bonds in the a-SiCN thin films were investigated experimentally and theoretically. A sharp transition from the predominantly $\mathrm{Si}-\mathrm{C}$ bonded structure to the $\mathrm{Si}-\mathrm{N}$ bonded structure was found during the deposition of $\mathrm{SiCN}$ thin films without and with $\mathrm{N}$ incorporation. The stronger affinity of $\mathrm{Si}-\mathrm{N}$ bonds over $\mathrm{Si}-\mathrm{C}$ bonds in the $\mathrm{SiCN}$ thin films were further verified by the analyses of local bonding configurations and crystal structures characterized by XPS and XRD, surface morphology by SEM and optical properties measured by micro-reflectometry. Finally, ab initio calculations for the simple $\mathrm{SiCN}$ cluster were performed to study the relative stabilities of $\mathrm{Si}-\mathrm{C}$ and $\mathrm{Si}-\mathrm{N}$ bonds in the a-SiCN network. The result indicates that the atomic structure with $\mathrm{Si}-\mathrm{N}$ bonding shows a more stable configuration compared to that with $\mathrm{Si}-\mathrm{C}$ bonding in terms of lower total energy and shorter bond length. From the experimental and theoretical studies, the origin of the complete absence of $\mathrm{Si}-\mathrm{C}$ bond in the $\mathrm{SiCN}$ thin films during deposition can be explained.

\section{References}

[1] A. Bendeddouche, R. Barjoan, E. Beche, R. Hillet, Surf. Coat. Technol. 111 (1911) 184

[2] R. Riedel, A. Greiner, G. Miehe, et al., Angew. Chem., Int. Ed. Engl. 36 (1997) 603.

[3] S. Chattopadhyay, L.C. Chen, C.T. Wu, K.H. Chen, J.S. Wu, Y.F. Chen, G. Lehmann, P. Hess, Appl. Phys. Lett. 79 (2001) 332.

[4] L.C. Chen, C.K. Chen, S.L. Wei, D.M. Bhusari, K.H. Chen, Y.F. Chen, Y.C. Jong, Y.S. Hunag, Appl. Phys. Lett. 72 (1998) 2463.

[5] H.C. Lo, J.J. Wu, C.Y. Wen, T.S. Wong, S.T. Lin, K.H. Chen, L.C. Chen, Diamond Relat. Mater. 10 (2001) 1916.

[6] M.L. Cohen, Phys. Rev., B 32 (1985) 7988; A.Y. Liu, M.L. Cohen, Science 245 (1989) 841.

[7] L.C. Chen, K.H. Chen, S.L. Wei, P.D. Kichambare, J.J. Wu, T.R. Lu, C.T. Kuo, Thin Solid Films 335-336 (1999) 112.

[8] Y.K. Chang, H.H. Hsieh, W.F. Pong, M.H. Tsai, K.H. Lee, T.E. Dann, F.Z. Chien, P.K. Tseng, K.L. Tsang, W.K. Su, L.C. Chen, S.L. Wei, K.H. Chen, D.M. Bhusari, Y.F. Chen, Phys. Rev. 58 (1998) 9018.

[9] L.C. Chen, K.H. Chen, J.J. Wu, D.M. Bhusari, M.C. Lin, in: H.S. Nalwa (Ed.), Chapter 2 in Handbook of Si-Based Materials and Devices, Academic Press, 2001, p. 74, Invited Book Chapter.

[10] G. Lehmann, P. Hess, J.J. Wu, C.T. Wu, T.S.S. Wong, K.H. Chen, L.C. Chen, H.Y. Lee, M. Amkreutz, Th. Frauenham, Phys. Rev., B 64 (2001) 165305 .

[11] C.W. Chen, M.H. Lee, L.C. Chen, K.H. Chen, Diamond Relat. Mater. 13 (2004) 1158. 